PSICOLOGIA, SAÚDE \& DOENÇAS, 2018, 19(3), 477-489

ISSN - 2182-8407

Sociedade Portuguesa de Psicologia da Saúde - SPPS - www.sp-ps.pt

DOI: http://dx.doi.org/10.15309/18psd190301

\title{
PORTUGUESE VALIDATION OF THE POSITIVE YOUTH DEVELOPMENT SHORT FORM (PYD-SF): A SHORTEN VERSION
}

\author{
Margarida Gaspar de Matos ${ }^{1}$, Teresa Santos ${ }^{1 \square}$, Marta Reis $^{2}$, Adilson Marques ${ }^{2}$, Gina Tomé ${ }^{2}$, Celeste Simões ${ }^{2}, \&$ \\ Nora Wiium ${ }^{3}$

\begin{abstract}
${ }^{1}$ Faculdade de Motricidade Humana (Equipa Aventura Social), Universidade de Lisboa, Portugal; Instituto de Saúde Ambiental, Faculdade de Medicina, Universidade de Lisboa, Portugal; William James Center for Research, ISPA - Instituto Universitário, Lisboa, Portugal,mmatos@fmh.ulisboa.pt,gaudi_t@hotmail.com

${ }^{2}$ Faculdade de Motricidade Humana (Equipa Aventura Social), Universidade de Lisboa, Portugal; Instituto de Saúde Ambiental, Faculdade de Medicina, Universidade de Lisboa, Portugal, reispsmarta@gmail.com, amarques@fmh.ulisboa.pt, ginatome@sapo.pt, csimoes@fmh.ulisboa.pt

${ }^{3}$ Department of Psychosocial Science, Faculty of Psychology, University of Bergen, Norway, Nora.Wiium@uib.no
\end{abstract}

\begin{abstract}
The Positive Youth Development-PYD concept highlighted the importance of strengthening internal and external developmental assets in the youth's contexts. This paper examines the psychometric properties of PYD-Short Form (PYD-SF) and its validation for Portuguese youths. The sample included 2700 college students (73.3\% girls), with a mean age of 21.3 \pm 2.79 years old. Exploratory-EFA and Confirmatory Factorial Analysis-CFA were conducted on the 34 items of the PYD-SF, a final shorten instrument (20 items) was achieved, and in the final model, CFA displayed an acceptable model fit $(\chi 2(174)=1349.20 ; \mathrm{GFI}=0.95$; $\mathrm{NFI}=0.95$; $\mathrm{CFI}=0.95$; and RMSEA=0.05, CI(RMSEA $)=0.05-0.06)$. The developed measure showed adequate psychometric properties (validity and reliability) to estimate PYD in Portuguese youths. Such instrument can be an advantage for its administration in larger population samples and a support for decision-making in professional practices and policies, encouraging a shift in youth care services approach: from a perspective focused on deficits/difficulties, towards a viewpoint focalized on possibilities/opportunities.
\end{abstract}

Keywords: adolescents, developmental assets, five cs, portugal, positive youth development short form (PYD-SF), youth

\section{VALIDAÇÃO PORTUGUESA DO POSITIVE YOUTH DEVELOPMENT SHORT FORM (PYD-SF): UMA VERSÃO REDUZIDA}

RESUMO: O conceito de Desenvolvimento Positivo em Jovens (Positive Youth Development -PYD) destacou a importância de fortalecer as "forças" internas e externas do desenvolvimento nos contextos da juventude. Este artigo examina as propriedades psicométricas de PYD-Short Form (PYD-SF) e sua validação para jovens Portugueses. A amostra incluiu 2700 estudantes universitários (73,3\% raparigas), com idade média e desviopadrão de 21,3 $\pm 2,79$ anos. Aos 34 items do PYD-SF foi aplicada a Análise Factorial Exploratória (AFE) e Análise Factorial Confirmatória (AFC), obtendo-se um instrumento final mais reduzido (com 20 itens). No modelo final, a AFC apresentou um modelo ajustado aceitável $\left(\chi^{2}(174)=1349,20, \mathrm{GFI}=0,95, \mathrm{NFI}=0,95, \mathrm{CFI}=0,95\right.$ e $\mathrm{RMSEA}=0,05, \mathrm{CI}$

Estrada da Costa 1495-688 Cruz Quebrada, Portugal. e-mail: gaudi_t@hotmail.com 
$($ RMSEA $)=0,05-0,06)$. O instrumento desenvolvido demonstrou propriedades psicométricas adequadas (validade e confiabilidade) para estimar o PYD em jovens Portugueses. Tal instrumento pode constituir-se uma vantagem para a sua administração em amostras populacionais maiores e um suporte para a tomada de decisões nas políticas e práticas profissionais, incentivando uma mudança na abordagem dos serviços de prestação de cuidados à juventude: de um ponto de vista focado em déficits/dificuldades, para uma perspectiva centrada em possibilidades/oportunidades.

Palavras-chave: adolescentes, "forças" do desenvolvimento, Cinco Cs, Portugal, Desenvolvimento Positivo, Positive Youth Development Short Form (PYD-SF), Jovens

Recebido em 23 de Janeiro de 2018/ Aceite em 25 de Setembro de 2018

In the past century the study of young people has been essentially outlined by a "deficit perspective", and within this approach, the concept of positive development was simply characterized by the absence or the decrease of problems (Geldhof et al., 2014). This perspective influenced policies, research and practice that were informed by measures used by programs and service organizations to assess youth functioning that was mainly based on risk and problem behaviours.

However, over the past two decades, the study of positive indicators of child well-being have significantly increased (Lippman, Moore, \& McIntosh, 2011). Additionally, it was largely recognized in the literature that youth programs and interventions would have limited impact if they mainly focus on risks and vulnerabilities. Thus, strength-based approaches have been found to be empowering and effective in various contexts (Benson, Scales, Hamilton, \& Sesma, 2006) and the interest in preventing youth problems and promoting healthy youth development has led practitioners, policy makers and researchers to develop a wide range of such approaches relying on several theoretical frameworks (Small \& Memmo, 2004).

Positive Youth Development-PYD has highlighted the importance of strengthening internal and external developmental assets that are embedded in the social ecology of an youth's networks and opportunities (Catalano, Berglund, Ryan, Lonczak, \& Hawkins, 2004; Small \& Memmo, 2004). Within the PYD approach, positive indicators such as the Search Institute's Developmental Assets model's (Benson, Leffert, Scales, \& Blyth, 1998) and the Five Cs model of PYD (Lerner et al., 2013; Lerner et al., 2011) have been widely studied. The Search Institute's Developmental Assets framework identified and comprised 40 relevant developmental assets (Benson et al., 1998), that reflect two major asset blocks, each consisting of 4 asset categories, respectively: 1) external assets (categories: support; empowerment; boundaries and expectations; constructive use of time); and 2) internal assets (categories: commitment to learning; positive values; social competencies; positive identity). In line the empirical evidence (Busseri \& Rose-Krasnor, 2009; Lerner et al., 2005; Lerner et al., 2011), the Five Cs (Lerner et al., 2013; Lerner et al., 2011) have been operationalized through the assessment of different Cs: 1) Competence, Confidence, Character, Connection and Caring. Competence is related to the positive view of one's actions in specific areas, such as social (interpersonal skills), academic (school grades, attendance and test scores), cognitive (cognitive abilities) and vocational (working habits, the search for career options and entrepreneurship). Confidence refers to an internal sense of overall positive self-worth, self-efficacy and identity. Character concerns the respect for societal and cultural values, the existence of standard ideas for correct behaviours, a general sense of morality (right/wrong) and integrity. Connection is related to relationships to self and others, positive bidirectional exchanges with the individual and other people, institutions, peers, family, school, and community. Caring refers to empathy and compassion for others (Lerner et al., 2005). When young people experience developmental assets that reflect an alignment of youth strengths 


\section{PORTUGUESE VALIDATION OF THE POSITIVE YOUTH}

with human and structural resources in youth context, positive development is facilitated. Accordingly, an adaptive developmental regulation process takes place where young people are able to contribute to the development of both self and society.

The Five Cs model of PYD has been used as a measure of positive outcomes, mainly in US samples, but also in non-US samples to some extend (Scales, 2011). Several versions of the PYD scale (for example the 78-item scale and the 34-item scale) have been developed and tested, and their psychometric properties have been largely verified (Geldhof et al., 2014; Lerner et al., 2014). The shorter version of the PYD scale was developed to promote among others, ease of use by researchers and practitioners (Geldhof et al., 2014). More studies looking at the psychometric properties of the shorter version are needed to ascertain its psychometric properties and applicability, especially in non-US contexts. This paper aims to examine the psychometric properties of the 34-item scale of PYD (PYD Short Form, PYD-SF) and its validation for Portuguese youths.

\section{METHOD}

\section{Study design}

The present validation was conducted within the project BePositive, a cross-sectional study and a part of the local national survey Health Behaviour in School-aged Children (HBSC/WHO) extended to Portuguese Universities (HBSC/JUnP). The HBSC/JUnP followed all the rules for research outlined in the Declaration of Helsinki (WMA, 2008) and was approved by the Ethics Commission of the Medicine Academic Center of Lisbon (Centro Académico de Medicina de Lisboa), CHLN/FMUL/IMM (Centro Hospitalar Lisboa Norte/Faculdade de Medicina de Lisboa/Instituto de Medicina Molecular). This University study is a result of the Portuguese partnership within the Positive Youth Development crossnational project (http://www.uib.no/en/rg/sipa/pydcrossnational), which involves more than twenty countries across Europe, Africa, Asia, the US and Latin America.

The cross-national project aims to: 1) examine the extent to which developmental (internal and external) assets are accessible to young people in different national contexts; 2) understand how these assets can be related to positive youth outcomes, such as the "5 Cs" of PYD (i.e., confidence, competence, character, caring and connection) and thriving indictors (e.g., school success, values diversity, resists danger and exhibit leadership); 3) highlight how positive outcomes are associated to young people's contribution to the development of the self and to the involving society.

\section{Participants}

A total of 2700 university students (1979 women), aged from 16 to 29 years old (21.3 \pm 2.8$)$ participated in the study. Most of the participants had Portuguese nationality $(n=2614)$, were born in Lisbon $(n=902)$, were living in an urban area $(n=1253)$, were graduate students $(n=1715)$ and had a middle socioeconomic status (SES) level $(\mathrm{n}=1828)$.

\section{Procedure}

Data collection was performed throughout an online survey, using the Limesurvey platform. Prior to data collection, the students were informed about the purpose of the study and informed consents were obtained. Informed consent from parents was sought as well where necessary. Students were assured 
confidentiality of their responses to the questionnaire and during the handling of the data. The survey followed all the rules for research outlined in the Declaration of Helsinki of the World Medical Association and was approved by the Ethics Commission of the Medicine Academic Centre of Lisbon of the Faculty of Medicine, University of Lisbon.

\section{Instrument}

The original version of PYD scale was developed using data from the 4-H Study in its different waves (Bowers et al., 2010; Jelicic, Bobek, Phelps, Lerner, \& Lerner, 2007; Lerner et al., 2005) that proposed and tested a higher-order measure of PYD, consisting of a five first-order latent constructs, each representing one of the Five Cs of PYD, published elsewhere (Geldhof et al., 2014). The structural component of PYD has been confirmed within the 4-H Study data set with early and mid-adolescence samples (i.e., from approximately 10-16 years) (Geldhof et al., 2014). The 78 items from the original scale were drawn and adapted from Profile of Students Life: Attitudes and Behaviours (PSL) (Institute, 2006), Self-Perception Profile for Adolescents (SPPA) (Harter, 1988), Teen Assessment Project (TAP) Survey Question Bank (Small \& Rodgers, 1995), Eisenberg Sympathy Scale (ESS) (Eisenberg et al., 1996), and Empathic Concern Subscale of the Interpersonal Reactivity Index (IRI) (Davis, 1980). The items for the "competence" were retrieved from the SPPA, the items for the "connection" from the PSL and TAP, the items for the "confidence" and "character" from the PSL and SPPA, and the items for the "caring" are a composite of modified items from the ESS and IRI.

More recently, a shorter version of this scale was developed - the Positive Youth Development Short Form (PYD-SF). The conducted analysis examined the measure across more waves of measurement, reduced the length of the scale from 78 to 34 items, scanned items rather than parcels and empirically tested the tenability of a higher-order factor structure. It was also emphasized a parsimonious representation of the Five Cs and created separate forms for early vs. middle/late adolescents (Geldhof et al., 2014).

The PYD-SF was translated from the original English version into Portuguese language (and back translation), and was then revised by a group of specialized experts within the area. Afterwards the psychometrics properties of the instrument were examined in terms of the frequency, internal consistency, reliability, correlation analysis, exploratory factor analysis and confirmatory factor analysis.

\section{MEASURES}

Detailed information concerning the measures of the PYD-SF is described in Table 1.

\section{Table 1.}

Original items of the PYD-SF (34 items)

\begin{tabular}{lll}
\hline $\begin{array}{l}\text { Factor } \\
\text { (Five Cs) }\end{array}$ & Original Items & Scoring* \\
\hline Confidence $^{1}$ & All in all, I am glad I am here. & \\
& When I am an adult, I'm sure I will have a good life. & \\
& I really like the way I look & 5-points \\
& I am good looking or attractive. & Likert scale \\
& I am happy with myself most of the time. & \\
\hline Competence $^{2}$ & I am very happy being the way I am. & 5-points \\
& I am just as smart as others my age. & Likert scale \\
& I could do well at just about any new outdoor activity I have not tried & 480
\end{tabular}




\section{PORTUGUESE VALIDATION OF THE POSITIVE YOUTH}

before.

I have a lot of friends.

I do very well in my class work at school.

I am popular with others my age.

I am better than others my age at sports.

Connection $^{3} \quad$ Teachers at school push me to be the best I can be.

Adults in my town or city listen what I have to say.

I feel my friends are good friends.

My friends care about me.

5-points

I have lots of good conversations with my parents.

Likert scale

In my family I feel useful and important.

I get a lot of encouragement at my school.

Adults in my town or city make me feel important.

Caring $^{4} \quad$ I feel sorry for other people who don't have what I have.

When I see someone being picked on, I feel sorry for them.

When I see someone being taken advantage of, I want to help them. 5-points

It bothers me when bad things happen to any person.

Likert scale

It makes me sad to see a person who doesn't have friends.

When I see another person who is hurt or upset, I feel sorry for them.

Character $^{1} \quad$ Knowing a lot about people of other races.

Enjoying being with people who are of a different race than I am.

I hardly ever do things I know I shouldn't do.

I usually act the way I am supposed to.

Helping to make the world a better place to live in.

5-points

Giving time and money to make life better for other people.

Likert scale

Doing what I believe is right even if my friends make fun of me.

Accepting responsibility for my actions when I make a mistake or get in trouble.

\footnotetext{
${ }^{1}$ The items from Confidence and Character were drawn and adapted from the Profile of Students Life: Attitudes and Behaviours (PSL)

(Institute, 2006) and Self-Perception Profile for Adolescents (SPPA) (Harter, 1988).

${ }^{2}$ The items from Competence were drawn and adapted from the Self-Perception Profile for Adolescents (SPPA) (Harter, 1988).

${ }^{3}$ The items from Connection were drawn and adapted from the Profile of Students Life: Attitudes and Behaviours (PSL) (Institute, 2006)

and Teen Assessment Project (TAP) Survey Question Bank (Small \& Rodgers, 1995).

${ }^{4}$ The items from Caring are a composite of modified items from the Eisenberg Sympathy Scale (ESS) (Eisenberg et al., 1996), and

Empathic Concern Subscale of the Interpersonal Reactivity Index (IRI) (Davis, 1983).

* The scoring system can be:

$1=$ Strongly disagree, $5=$ Strongly agree;

$1=$ Almost never true or never true, $5=$ Always true;

$1=$ Not all like me, $5=$ Very much like me;

$1=$ Not important, $5=$ Extremely important.
}

\section{Data analysis}

Data from Limesurvey was transferred to an electronic data file. All variables were checked for data inaccuracy by running SPSS frequencies, and afterwards, an analysis on missing values was conducted. Descriptive analysis (means, standard deviation and percentage) were used to characterize the sample. All data were tested for normality prior to any analyses using Kolmogorov-Smirnov tests, as well as Levene's test for the homogeneity of the variance. To examine the factor structure of the PYD-SF, Exploratory Factor Analysis (EFA) with Maximum Likelihood Estimation and Oblimin rotation was used. The 
Kaiser-Guttman rule was used to retain factors with eigenvalues of $\geq 1.00$. Cronbach's alpha was computed to examine internal consistency of the PYD-SF dimensions (Five Cs).

A Confirmatory Factorial Analysis (CFA) was performed to confirm the Five Cs structure of the PYDSF. The Maximum Estimation procedure was used to derive parameter estimates in PYD-SF model. The analysis were performed on the covariance matrix. For model identification purposes, a scale was assigned for each latent variable by setting one of its factor loadings to unity. Multiple fit indexes were used to evaluate goodness of fit of models tested in the study: chi-square statistics $\left(\chi^{2}\right)$, comparative fit index (CFI), non-normed fit index (NNFI), root mean square error of approximation (RMSEA), and standardized root mean squared residual (SRMR). The cross validity of the model was formally tested for measure and structural invariance between the two split halves of the sample. The analyses were conducted using the SPSS 24.0 (Statistical Package for Social Sciences) and the Structural Equation Modelling with software AMOS 24.0. The significance level was set at $\mathrm{p}<0.05$.

\section{RESULTS}

\section{Exploratory factor analysis}

Data from the 34 items were subjected to an Exploratory Factor Analysis (EFA). The Maximum Likelihood extraction with Oblimin Rotation produced a nine-factor solution based on eigenvalues greater than 1, and accounted for $68.08 \%$ of the explained variance. The Kaiser-Meyer-Olkin (KMO) measure of sampling adequacy was satisfactory $(\mathrm{KMO}=0.84)$. Bartlett's test of sphericity $(\chi 2(561)=47618.85$, $\mathrm{p}<0.001$ ) indicated that items correlation were sufficiently large for factor analysis (Field, 2013). Although the EFA resulted in a nine-factor solution, Lerner's theory defined the existence of 5 dimensions, considered the Five Cs (Lerner et al., 2013; Lerner et al., 2011). The obtained solution in the present study showed that the items were not well represented according to Lerner's theory and were spread between nine-factors. Thus, an effort was made to maintain the Five Cs defined in the theory.

Three items with communalities lower than 0.50 were subsequently removed, and an analysis to assess the internal consistency of each dimension (Chronbach's Alpha) was run. The analysis showed that the deletion of the items with a worse representation would increase the Alpha values, in each dimension. Therefore, ten items were deleted. With the remaining 21 items, another EFA was performed. The Maximum Likelihood extraction with Oblimin Rotation produced a four-factor solution based on eigenvalues greater than 1 , and accounted for $60.57 \%$ of the explained variance. The Kaiser-Meyer-Olkin (KMO) measure of sampling adequacy was good $(\mathrm{KMO}=0.86)$. Bartlett's test of sphericity was $(\chi 2(210)=27568.67, \mathrm{p}<0.001)$. Items were considered to have loaded a factor if values exceeded 0.50 and were considered uniquely loaded if cross-loadings on other factors were less than 0.50 . The first component was named "Confidence-Competence" and comprised nine items. The other components were named "Character", "Connection" and "Caring", each one consisting of four items. The exploratory factor analysis loadings for PYD are presented in Table 2. 
Table 2.

Exploratory factor analysis loadings for PYD

\begin{tabular}{|c|c|c|c|c|}
\hline & \multicolumn{4}{|c|}{ Components } \\
\hline & $\mathrm{CF}$ and $\mathrm{CP}$ & $\mathrm{CH}$ & $\mathrm{CN}$ & $\mathrm{CA}$ \\
\hline I am better than others my age at sports. & 0.95 & & & \\
\hline I am happy with myself most of the time. & 0.82 & & & \\
\hline I am good looking or attractive. & 0.78 & & & \\
\hline I am very happy being the way I am. & 0.77 & & & \\
\hline I do very well in my class work at school. & 0.75 & & & \\
\hline I am popular with others my age. & 0.75 & & & \\
\hline I have a lot of friends. & 0.75 & & & \\
\hline I could do well at just about any new athletic activity. & 0.71 & & & \\
\hline I really like the way I look. & 0.70 & & & \\
\hline Doing what I believe is right even if my friends make fun of me. & & 0.85 & & \\
\hline Helping to make the world a better place to live in. & & 0.81 & & \\
\hline $\begin{array}{l}\text { Accepting responsibility for my actions when I make a mistake or get in } \\
\text { trouble. }\end{array}$ & & 0.81 & & \\
\hline Giving time and money to make life better for other people. & & 0.73 & & \\
\hline In my family I feel useful and important. & & & 0.84 & \\
\hline I have lots of good conversations with my parents. & & & 0.84 & \\
\hline Adults in my town or city make me feel important. & & & 0.66 & \\
\hline I get a lot of encouragement at my school. & & & 0.63 & \\
\hline It bothers me when bad things happen to any person. & & & & 0.79 \\
\hline When I see someone being taken advantage of, I want to help them. & & & & 0.75 \\
\hline When I see another person who is hurt or upset, I feel sorry for them. & & & & 0.73 \\
\hline It makes me sad to see a person who doesn't have friends. & & & & 0.67 \\
\hline
\end{tabular}

Abbreviations: $\mathrm{CF}$, confidence, $\mathrm{CP}$, competence; $\mathrm{CH}$, character; $\mathrm{CN}$, connection; $\mathrm{CA}$, caring

Extraction Method: Principal Component Analysis.

Rotation Method: Oblimin with Kaiser Normalization.

\section{Internal Consistency}

To further examine the reliability of the items reflecting the PYD components, Cronbach's Alpha was computed for each component. For such analysis and despite the four-factor solution, that has been obtained in previous analysis, the authors decided to have a conservative approach, maintaining the Five Cs structure based on Lerner's theory (Lerner, Phelps, Forman, \& Bowers, 2009; Lerner et al., 2013; Lerner et al., 2011). This means that the factor "Confidence-Competence" was divided into two separated components, respectively "Confidence" and "Competence". "Confidence" had an internal consistency of $\alpha=0.83$, "Competence" $\alpha=0.87$, "Character" $\alpha=0.82$, "Connection" $\alpha=0.74$, "Caring" $\alpha=0.74$. Considering that each component included four and one of them included five items, the internal consistencies can be considered as adequate.

\section{Confirmatory factor analysis}

In a separate analysis, a CFA was conducted on data from the 2700 participants. Multiple fit indexes were used as guides to evaluate goodness of fit of models tested in the study $(\chi 2$, GFI, NFI, CFI and 
RMSEA). The fit indices for both the original and modified models are showed in table 3 . The fit indices of the original model were indicative of a poor fitting model $(\chi 2(179)=3486.10 ; \mathrm{GFI}=0.89 ; \mathrm{NFI}=0.87$; $\mathrm{CFI}=0.88$; and RMSEA=0.08, $\mathrm{CI}(\mathrm{RMSEA})=0.08-0.09)$. Modification indices were examined, and model fit was improved by adding arrows between the highest error's covariance in each dimension. Although the Chi-Square values remained poor, the model fit generally improved $(\chi 2(174)=2370.72$; GFI $=0.92$; $\mathrm{NFI}=0.91$; CFI=0.92; and RMSEA=0.07, CI(RMSEA)=0.06-0.07). Based on modification indices, the error's covariance among items were inspected again. The modification indices suggested that one item from Competence was also saturated in Confidence and also showed a higher error covariance with other items from the Confidence and Competence. Thus, this item was deleted and the resulting CFA displayed acceptable model fit $(\chi 2(174)=1349.20 ; \quad \mathrm{GFI}=0.95 ; \mathrm{NFI}=0.95 ; \mathrm{CFI}=0.95 ; \quad$ and $\mathrm{RMSEA}=0.05$, $\mathrm{CI}(\mathrm{RMSEA})=0.05-0.06)$. The $\chi 2 / \mathrm{df}$ values remained poor, however, $\chi 2 / \mathrm{df}$ is not considered to be a useful fit index (Hayduk, Cummings, Boadu, Pazderka-Robinson, \& Boulianne, 2007), because it is affected by the sample size and the distribution of variables. The indices for evaluating goodness of fit of the models in the different phases are presented in Table 3.

Table 3.

Indices for evaluating goodness of fit of models in different phases

\begin{tabular}{llllll}
\hline Models & $\chi^{\mathbf{2}}(\mathbf{g l})$ & GFI & NFI & CFI & RMSEA (90\% IC) \\
\hline Step 1 & $3486.10(179)$ & 0.89 & 0.87 & 0.88 & $0.08(0.08-0.09)$ \\
Step 2 & $2370.72(174)$ & 0.92 & 0.91 & 0.92 & $0.07(0.06-0.07)$ \\
Step 3 & $1349.20(174)$ & 0.95 & 0.95 & 0.95 & $0.05(0.05-0.06)$ \\
\hline
\end{tabular}

Abreviations: GFI, goodness of fit index; NFI, normal fit index; CFI, comparative fit index; RMSEA, root mean square error of approximation

The composite reliability of the factors was high for the following $\mathrm{C}$ components: Confidence (0.83), Competence (0.85), Character (0.82); and adequate for the following $\mathrm{C}$ components: Connection (0.74) and Caring (0.74). The discriminant validity of the factors was tested by the comparing the average variance extracted with the squared correlation among factors. The factors showed discriminant validity between each other, with the exception of the C's Confidence and Competence. The relation between Confidence and Competence had been already observed in the EFA. In the current analysis, these two Cs were not found to be separate components or factors, although theoretically two constructs surfaced in Lerner's theory. Aiming to maintain theoretical coherence and to preserve the structure as close as possible to the original, Confidence and Competence were retained as two constructs, even though they had no discriminating validity.

The final model is shown in Figure 1. 


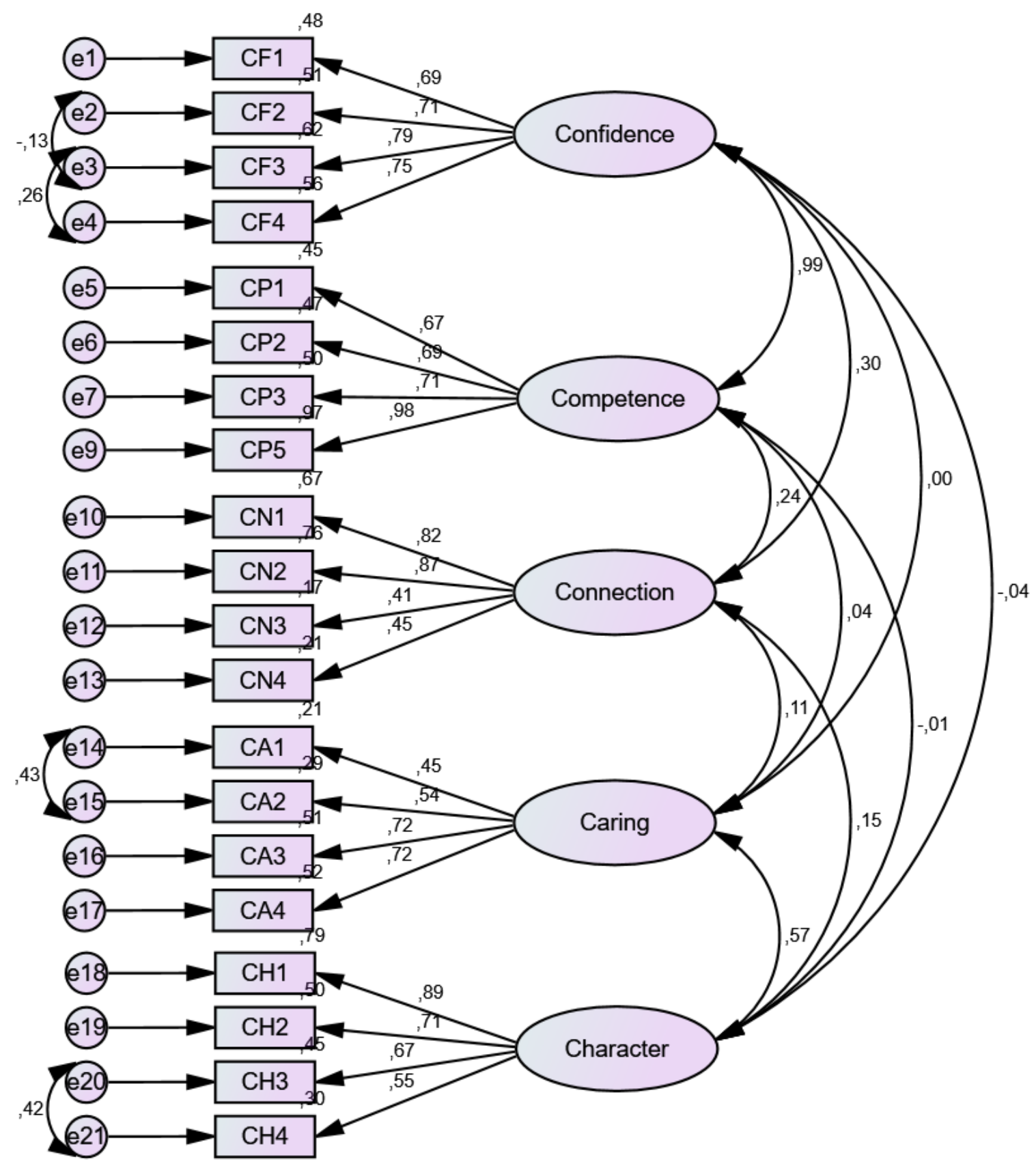

\section{Figure 1.}

Path diagram of the model for PYD with standardized values for coefficients and covariates

In order to cross validate the results, measurement and structural invariance were tested on the two split halves of the sample. To test for measurement invariance, the formal structure from the calibration of the final standardized solution was examined. Fit indices for this multi-group model were good, thus proving its validity for interpreting the PYD model $(\chi 2(310)=2079.08 ; \mathrm{GFI}=0.93$; NFI $=0.92$; $\mathrm{CFI}=0.93$; and RMSEA=0.05, CI(RMSEA $)=0.04-0.05)$.

Afterwards, a psychometric analysis for internal consistency was performed and the following Cronbach's Alphas were achieved: $\alpha=0.83$ for Confidence, $\alpha=0.85$ for Competence, $\alpha=0.74$ for 
Connection, $\alpha=0.74$ for Caring, $\alpha=0.82$ for Character, and $\alpha=0.83$ for the total PYD score. These values were in line with the coefficient of internal consistency obtained in the original Portuguese PYD-SF (34 items), specifically $\alpha=0.77$ for Confidence, $\alpha=0.86$ for Competence, $\alpha=0.80$ for Connection, $\alpha=0.77$ for Caring, $\alpha=0.67$ for Character, and $\alpha=0.87$ for the total PYD score. The final shorten version of the PYDSF (20 items) in Portuguese can be found in the Supplementary File 1.

\section{DISCUSSION}

The purpose of this paper was to examine the psychometric properties of an assessment scale use to address the concept of PYD (PYD Short Form, PYD-SF) and its validation in a Portuguese sample. The research was conducted with a sample of 2700 university students with a mean age of 21.3 years old.

Throughout the past century, the study of young people has been essentially outlined by a "deficit perspective" (Geldhof et al., 2014; Moore, Lippman, \& Brown, 2004). However, in the last two decades, the study of positive indicators of child well-being have significantly improved (Lippman, Moore, \& McIntosh, 2011). This current study was based on a theoretically structure of PYD categorized into Five Cs: Confidence, Competence, Connection, Caring and Character, and an EFA, a CFA and an analysis on internal consistency were conducted. These analyses examined, empirically tested and confirmed the tenability of a higher-order factor structure of the PYD-SF and also allowed to reduce the length of the scale.

Data from the 34 items PYD-SF were subjected to EFA and a good nine-factor solution was obtained, instead of the components of PYD. Making an effort to keep in line with the theoretical perspective, communalities of the items were computed, items were deleted and EFA was run on the remaining 21 items. A good four-factor solution was obtained. Items were considered loaded to have loaded onto a factor if factor loading exceeded 0.50 and were considered uniquely loaded if cross-loadings on other factors were less than 0.50 . To further examine the reliability of the items comprising the PYD components, Cronbach's Alpha was computed for each component and all the components showed an adequate internal consistency. Based on the results from the aforementioned analyses, the authors decided to have a conservative approach by maintaining the Five Cs structure. Thus, the factor "ConfidenceCompetence" in the four-factor model was divided into two separated components, "Confidence" and "Competence".

Next, a CFA was performed and multiple fit indexes were used as guides to evaluate goodness of fit of the models that were tested. Here, one more item was deleted and the resulting CFA displayed an acceptable model fit. The RMSEA was equal to 0.05 , the upper limit of $90 \%$ confidence interval was lower than .04, and CFI was higher than 0.90 . The composite reliability of the factors demonstrated to be high $(\geq 0.70)$ for all the five Cs.

Afterwards, internal consistency was examined and the Cronbach's Alphas $(\geq 0.74)$ that were achieved for the Five Cs and for the total PYD score, were comparable to those obtained in the original Portuguese PYD-SF (34 items). In addition, similar statistical analysis that were previously run on the PYD-SF (34 items) regarding gender, age, and socioeconomic status (SES) (Matos, Santos, \& Reis, 2017) were repeated on the reduced version of PYD-SF (20 items), and similar results were found and will be target in a future publication.

The results confirm a model with a five-factor structure, like the one obtained in the original PYD-SF scale, but at the same time present a shortened version with 20 items that have adequate psychometric properties and appears to reflect a valid, reliable and sensitive instrument to estimate PYD in Portuguese youths. Compared to the version with 34 items version, to have a shorter version of 20 items can represent a major advantage for its administration in larger population samples, constituting an interesting 


\section{PORTUGUESE VALIDATION OF THE POSITIVE YOUTH}

option for professionals, because it can be more cost-effective. It is expected in the future, that comparisons of instruments from the several countries included in the cross-national PYD project can be done.

Moreover, it is suggested that to have data on PYD in youths through a reliable instrument is one of the key issues to implement strength-based approaches that have been found to be empowering and effective in various contexts (Benson et al., 2006). In addition, it may also help health and education policy makers to prevent youth problems and promote their health (Small \& Memmo, 2004).

\section{Limitations and Strengths}

Despite the attempt to ensure the psychometric quality of the PYD-SF, this study has some limitations. First, in spite of the confirmation of the Five Cs structure, the original items were retrieved from multiple instrument sources and accordingly were scored using different metrics. In the present PYD-SF (34 items) scale an attempt to reduce this limitation was achieved by finding a standardized score system for all items in a 5-point Likert scale, in line with the literature suggestion (Geldorf et al., 2014). Second, the non-representativeness of the sample and the cross-sectional study design can limit the extent to which the findings of the present study can be generalized. In addition, the sample consisted of youths from 16 to 26 years old and the results might differ across gender ad age groups if these multi-group analyses were done. These issues are to be addressed in the future.

Nevertheless, this study has numerous strengths. First, it makes use of a reliable and valid instrument to assess PYD in Portuguese youths, which provides innovation and novelty in this area, constituting a pioneer initiative in Portugal. Second, its inclusion in a cross-national project allows the study of cultural diversity and the possibility to learn about the process of validation in the other countries. Third, to have a short, reliable and valid instrument to measure PYD (20 items) can be a major advantage due to its ease of administration in large population studies.

The PYD perspective is being increasingly adopted by researchers of youth development, developmental scientists, youth-services and policy makers. Therefore, it is crucial to have a valid, objective and reliable instruments to measure youth positive development, with good psychometric properties. The short PYD version (20 items) presented in this study provide this instrument to assess youth's positive attributes that are categorized in the Five Cs. It is highlighted that this short version can be easily administrated by researchers and practitioners in several contexts, aiming to improve the scientific knowledge on the area of youth development, and also the implementation of more effective interventions for youths as well as creating a more solid basis for public policies. It is expected that such information may actively contribute to facilitate and encourage the necessary shift of approach in youth care services: from a perspective focused on deficits and difficulties, towards a viewpoint that focuses on possibilities and opportunities for youths to develop their full potential.

\section{COMPETING INTERESTS}

None of the authors reported any financial interests or potential conflicts of interest. 
Margarida Gaspar de Matos, Teresa Santos, Marta Reis, Adilson Marques, Gina Tomé, Celeste Simões, \& Nora Wiium

\section{ACKNOWLEDGEMENTS}

A special thanks to all the universities, students, teachers and experts who participated in this study. To National experts for their collaboration in revising the methodology and the used instruments. To the HBSC/WHO network (www.hbsc.org) whose survey was partially used for this purpose. To Nora Wiium and the other colleagues from PYD international: http://www.uib.no/en/rg/sipa/pydcrossnational for all support and inspiration.

\section{REFERENCES}

Benson, P. L., Leffert, N., Scales, P. C., \& Blyth, D. A. (1998). Beyond the village rhetoric: Creating healthy communities for children and adolescents. Applied Developmental Science, 2, 138-159.

Benson, P. L., Scales, P. C., Hamilton, S. F., \& Sesma, A. (2006). Positive youth development: Theory, research and application. In W. Damon \& R. M. Lerner (Eds.), Handbook of child psychology, (pp. 894-941). New York: Wiley.

Bowers, E. P., Li, Y., Kiely, M. K., Brittian, A., Lerner, J. V., \& Lerner, R. M. (2010). The Five Cs model of positive youth development: a longitudinal analysis of confirmatory factor structure and measurement invariance. J Youth Adolesc, 39(7), 720-735.

Busseri, M. A., \& Rose-Krasnor, L. (2009). Breadth and intensity: salient, separable, and developmentally significant dimensions of structured youth activity involvement. Br J Dev Psychol, 27(Pt 4), 907-933.

Catalano, R. F., Berglund, M. L., Ryan, J. A. M., Lonczak, H. S., \& Hawkins, J. D. (2004). Positive youth development in the United States: Research findings on evaluations of positive youth development programs. Annals of the American Academy of Political and Social Science, 591, 98-124.

Davis, M. (1980). A multidimensional approach to individual differences in empathy. Catalog of Selected Documents in Psychology, 10(4), 1-17.

Eisenberg, N., Fabes, R. A., Murphy, B., Karbon, M., Smith, M., \& Maszk, P. (1996). The relations of children's dispositional empathy-related responding to their emotionality, regulation, and social functioning. Developmental Psychology, 32(2), 195-209.

Field, A. (2013). Discovering statistics using IBM SPSS statistics (4th ed.). London: Sage.

Geldhof, G. J., Bowers, E. P., Boyd, M. J., Mueller, M. K., Napolitano, C. M., Schmid, K. L., . . Lerner, R. M. (2014). Creation of short and very short measures of the five Cs of positive youth development. Journal of Research on Adolescence, 24(1), 163-176.

Harter, S. (1988). Manual for the self-perception profile for adolescents (SPPA). Denver, CO: University of Denver.

Hayduk, L., Cummings, G., Boadu, K., Pazderka-Robinson, H., \& Boulianne, S. (2007). Testing! testing! one, two, three - Testing the theory in structural equation models! Personality and Individual Differences, 42(5), 841-850.

Institute, S. (2006). 40 development assents for adolescents. Minneapolis, MN: Search Institute.

Jelicic, H., Bobek, D. L., Phelps, E., Lerner, R. M., \& Lerner, J. V. (2007). Using positive youth development to predict contribution and risk behaviors in early adolescence: Findings from the first two waves of the 4-H study of positive youth development. International Journal of Behavioral Development, 31(3), 263-273.

Lerner, J. V., Bowers, E. P., Minor, K., Boyd, M. J., Mueller, M. K., Schmid, K. L., . . Lerner, R. M. (2013). Positive youth development: processes, philosophies, and programs. In R. M. Lerner, M. A. 


\section{PORTUGUESE VALIDATION OF THE POSITIVE YOUTH}

Easterbrooks \& J. Mistry (Eds.), Handbook of psychology, volume 6: Developmental Psychology (pp. 365-392). Hoboken, NJ: Wiley.

Lerner, R. M., Lerner, J. V., Almerigi, J. B., Theokas, C., Phelps, E., Gestsdottir, S., . . . von Eye, A. (2005). Positive Youth Development, participation in community youth development programs, and community contributions of fifth-grade adolescents: Findings from the first wave of the 4-H study of positive youth development. Journal of Early Adolescence, 25(1), 17-71.

Lerner, R. M., Lerner, J. V., Lewin-Bizan, S., Bowers, E. P., Boyd, M., Mueller, M., . . Napolitano, C. (2011). Positive youth development: Processes, programs, and problematics. Journal of Youth Development, 6(3), 40-64.

Lerner, R. M., Wang, J., Chase, P. A., Gutierrez, A. S., Harris, E. M., Rubin, R. O., \& Yalin, C. (2014). Using relational developmental systems theory to link program goals, activities, and outcomes: The sample case of the 4-H study of positive youth development. New Directions for Youth Development, $144,17-30$.

Lippman, L. H., Moore, K. A., \& McIntosh, H. (2011). Positive Indicators of Child Well-Being: A Conceptual Framework, Measures, and Methodological Issues. Applied Research in Quality of Life, 6(4), 425-449.

Matos, M. G., Santos, T., \& Reis, M. (2017). BePositive project: Positive Youth Development (PYD) in adolescents. Portuguese report. Saarbrucken: Lambert Academic Publishing.

Moore, K. A., Lippman, L., \& Brown, B. (2004). Indicators of child well-being: The promise for positive youth development. Annals of the American Academy of Political and Social Science, 591, 125-145.

Scales, P. C. (2011). Youth developmental assets in global perspective: results from international adaptations of the developmental assets profile. Child Indicators Research, 4(4), 619-645.

Small, S., \& Memmo, M. (2004). Contemporary models of youth development and problem prevention: Toward an integration of terms, concepts, and models. Family Relations, 53(1), 3-11.

Small, S. A., \& Rodgers, K. B. (1995). Teen Assessment Project (TAP) survey question bank. Madison: University of Wisconsin-Madison.

WMA - World Medical Association (2008). World medical association declaration of Helsinki: Ethical principles for medical research involving human subjects. Retrieved from http://www.wma.net/en/20activities/10ethics/10helsinki/ 